\title{
Sensing mechanism of hydrogen sensors based on Pd loaded tungsten oxide $\left(\mathrm{Pd}-\mathrm{WO}_{3}\right)$
}

\author{
A. Boudiba ${ }^{1}$, P. Roussel ${ }^{4}$, C. Zhang ${ }^{1}$, M.-G. Olivier ${ }^{1,3}$, R. Snyders ${ }^{2,3}$, M. Debliquy $^{1}$ \\ ${ }^{1}$ Service de Science des Matériaux, Faculté Polytechnique, Université de Mons, 7000 Mons, Belgium. \\ ${ }^{2}$ Laboratoire de Chimie des Interactions Plasma-Surface, Université de Mons, 7000 Mons, Belgium. \\ ${ }^{3}$ Materia Nova Research Centre, 7000, Mons, Belgium. \\ ${ }^{4}$ Ecole Nationale Supérieure de Chimie de Lille, Unité de Catalyse et Chimie du Solide - UMR CNRS \\ 8181, Villeneuve d'Ascq, France. \\ Abdelhamid.boudiba@umons.ac.be \\ Abdelhamid.boudiba@gmail.com
}

\begin{abstract}
This paper presents a study on hydrogen sensing mechanism of Pd-loaded tungsten oxide nanocomposites $\left(\mathrm{Pd}-\mathrm{WO}_{3}\right)$. The $\mathrm{Pd}-\mathrm{WO}_{3}$ nanocomposites were prepared and characterized by SEM, TEM, XRD and XPS analyses. The responses to 25-200 ppm hydrogen were measured at $50 \%$ relative humidity. The changes in the optical properties and crystal phases of $\mathrm{Pd}-\mathrm{WO}_{3}$ in contact with hydrogen were investigated by UV-Vis-IR spectroscopy and XRD. In-situ characterization were carried out at different conditions, $3 \% \mathrm{H}_{2}$ diluted in synthetic air/or nitrogen at temperatures ranging from 25 to $200^{\circ} \mathrm{C}$. The changes in the crystal phases (formation of hydrogen tungsten bronze) in the surface or in bulk were correlated with the electrical responses. More experimental results and explanations will be presented and discussed.
\end{abstract}

Key words: $\mathrm{WO}_{3}, \mathrm{Pd}-\mathrm{WO}_{3}$, hydrogen sensors, sensing mechanism.

\section{Introduction}

The sensing mechanism of gas sensors based on modified metal oxides by noble catalyst (NM-MO) is reported in the literature by several authors $[1,2]$. It is accepted that the mechanism is associated to the change of the resistance in contact with the chemisorbed oxygen and gases species on the surface of the metal oxide. In NM-MO such as $\left(\mathrm{Pd}-\mathrm{SnO}_{2}\right)$, the catalyst on the surface of the metal oxide promote the oxygen species $\left(\mathrm{O}^{-}, \mathrm{O}_{2}^{-}, \mathrm{O}^{2-}\right)$ presented on the surface, resulting in an electrons depletion region on the surface of the sensor material. When the surface of gas sensor is exposed to reducing gases (CO, ethanol, methanol...ext.), the oxygen species react with the gases and electrons are feed back to the semiconductor, which increases the sensor conductivity.

For hydrogen, in addition to the reaction on the surface of the sensor between oxygen species and hydrogen, the catalyst dissociates $\mathrm{H}_{2}$ which reacts with $\mathrm{WO}_{3}$ to form blue tungsten bronze $[1,2]$. The formation of the tungsten bronze can be limited at the surface of the sensitive materials or in the bulk depending on the atmospheric conditions. In this work, $\mathrm{Pd}-\mathrm{WO}_{3}$ nanocomposites were prepared, the changes in the optical properties on the surface and crystal phases of $\mathrm{Pd}-\mathrm{WO}_{3}$ in contact with hydrogen were demonstrated in the surface and in the bulk of $\mathrm{WO}_{3}$ depending on the atmospheric conditions. The effects of the temperature (from $27^{\circ} \mathrm{C}$ to $200^{\circ} \mathrm{C}$ ), the catalyst (pure and modified $\mathrm{Pd}-\mathrm{WO}_{3}$ ) and the oxygen (in the air or in nitrogen atmospheres) on the electrical and optical properties were also studied.

\section{Experimental}

$\mathrm{Pd}-\mathrm{WO}_{3}$ nanocomposites were prepared and characterized [3], $\mathrm{WO}_{3}$ nanoparticles were obtained by direct precipitation of $0.5 \mathrm{M}$ $\mathrm{Na}_{2} \mathrm{WO}_{4}$ at $80^{\circ} \mathrm{C}$ in hydrochloric acid (3M). The resulting product was washed several times, dried and annealed in air at $400^{\circ} \mathrm{C}$ for 4 hours.

To prepare $\mathrm{Pd}$-doped $\mathrm{WO}_{3}$ coatings, palladium chloride salt was dissolved and dispersed in organic solvent (terpineol) with $\mathrm{WO}_{3}$ nanopowder using sonication. The resultant dispersion with 2 wt $\%$ Pd loading was screenprinted on alumina substrates fitted with gold electrodes and platinum heating element [3]. 
$\mathrm{WO}_{3}$ and $\mathrm{Pd}-\mathrm{WO}_{3}$ sensors were annealed at $400^{\circ} \mathrm{C}$ for 12 hours.

For gas sensing tests, the $\mathrm{Pd}$-doped $\mathrm{WO}_{3}$ coatings are heated at $200^{\circ} \mathrm{C}$ for 24 hours in ambient air before their exposition to the gases into a Teflon chamber (the setup is reported in reference [4]).

The response of the senor to $25-200 \mathrm{ppm}$ hydrogen in air was measured at various relative humidities as reported previously [3]. Vis-NIR spectra in reflection of the same powders were also measured at room temperature and at $200^{\circ} \mathrm{C}$ in contact with 4000 ppm of hydrogen diluted in synthetic air. XRD using $\mathrm{CuK}_{\alpha}$ radiation were carried out on the same powder from 27 to $200^{\circ} \mathrm{C}$ in contact with hydrogen as following: condition (I): $3 \%$ hydrogen diluted in nitrogen and condition (II): $3 \%$ hydrogen diluted in synthetic air. XRD of pure $\mathrm{WO}_{3}$ were also performed from 27 to $200^{\circ} \mathrm{C}$ in contact with $3 \%$ of hydrogen diluted in synthetic air or in nitrogen (conditions (I) and (II)).

\section{Results and discussions}

The electrical response to $25-200 \mathrm{ppm}$ hydrogen is presented in Fig.1. It is well observed that the resistance of the sensors decreases once in contact with hydrogen. The changes in the resistance in contact with hydrogen can be attributed to two phenomena (I): the oxygen species chemisorbed on the surface of $\mathrm{WO}_{3}$ reacts with hydrogen to form water vapor, the electrons trapped by oxygen feed back to the conductance band and (II): the dissociated hydrogen on the catalyst reacts with $\mathrm{WO}_{3}$ to form hydrogen tungsten bronze. Both mechanisms result in an increase of the sensor conductivity. In this work, the mechanism (II) was observed on the surface of $\mathrm{Pd}^{-} \mathrm{WO}_{3}$ in contact with hydrogen (4000 ppm of $\mathrm{H}_{2}$ diluted in synthetic air). As shown on Fig. 3, the reflectance of $\mathrm{Pd}^{-} \mathrm{WO}_{3}$ surface decreased from $40 \%$ to $25 \%$ at $\lambda=2000 \mathrm{~nm}$. This color change is due to the reduction of $\mathrm{W}^{+6}$ to $\mathrm{W}^{+5}$ or $\mathrm{W}^{+4}$ on the surface. In the bulk, the XRD data showed that the diffusion of hydrogen and its insertion into $\mathrm{WO}_{3}$ lattice is governed essentially by the presence of oxygen as explained afterwards. The XRD data presented in Fig.4 showed that $\mathrm{Pd}-\mathrm{WO}_{3}$ is transformed to $\mathrm{H}_{\mathrm{x}} \mathrm{WO}_{3-\mathrm{y}}$ after 60 min of contact with $3 \%$ diluted hydrogen in nitrogen, no change is observed if $\mathrm{Pd}$ is not added. In the presence of oxygen (3\% $\mathrm{H}_{2}$ diluted in air), no change in the crystal phase is observed, the monoclinic $\mathrm{WO}_{3}$ phase remains even after 16 hours at $200^{\circ} \mathrm{C}$. Tab. 1 summarizes the change in the crystal phase of monoclinic $\mathrm{WO}_{3}$ under different operating conditions. The tetragonal hydrogen tungsten bronze phase was observed only for $\mathrm{NM}-\mathrm{WO}_{3}$ in condition (I): temperature ranging from 27 to $200^{\circ} \mathrm{C}$ in contact with diluted hydrogen in nitrogen atmosphere. The modification of the optical spectra and no change of XRD mean that the formation of the bronze is limited to the surface when oxygen is present. It should be noted that no change in the crystal phase is observed of pure $\mathrm{WO}_{3}$ for the two conditions (I) and (II).

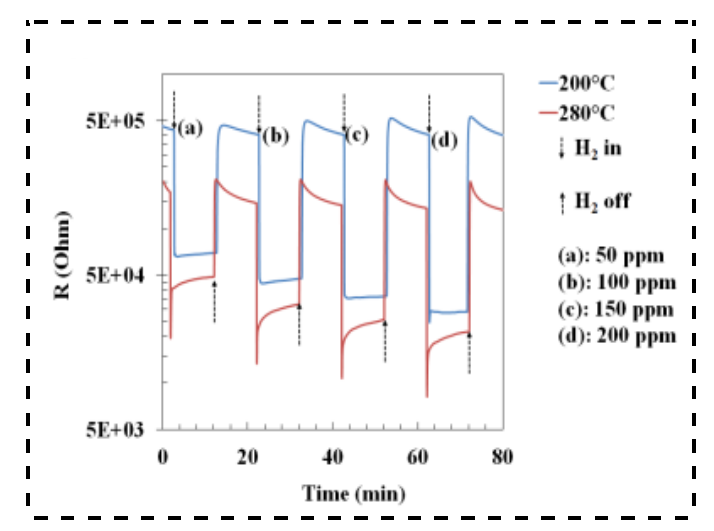

Fig. 1. Resistance changes of $\mathrm{Pd}-\mathrm{WO}_{3}$ films in contact with $\mathrm{H}_{2}$ versus hydrogen concentration at 200 and $280^{\circ} \mathrm{C}(\mathrm{RH}=50 \%)$.

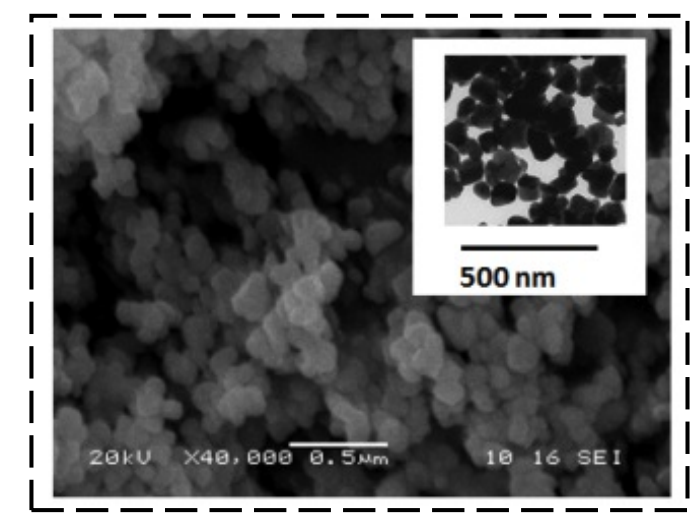

Fig. 2. SEM and TEM images of $W_{3}$ nanoparticles annealed in air at $400^{\circ} \mathrm{C}$ for 4 hours.

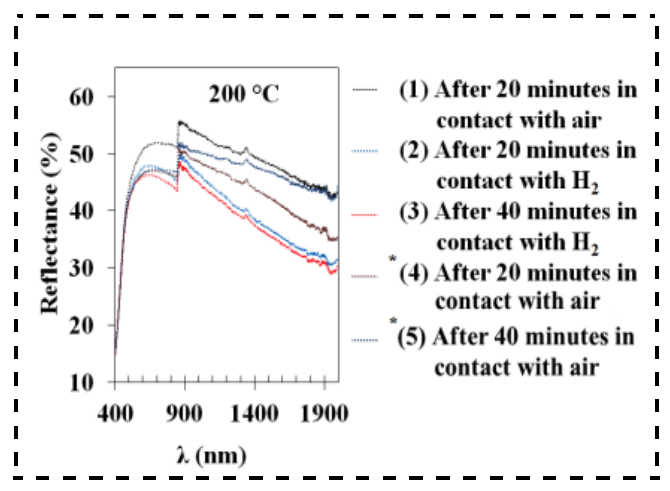

Fig. 3. Evolution of the reflectance of the $\mathrm{Pd}-\mathrm{WO}_{3}$ coatings in contact with $\mathrm{H}_{2}$ in air at $200^{\circ} \mathrm{C}$, ( $\left(^{*}\right)$ the tests were recorded after 60 minutes of contact with hydrogen. 


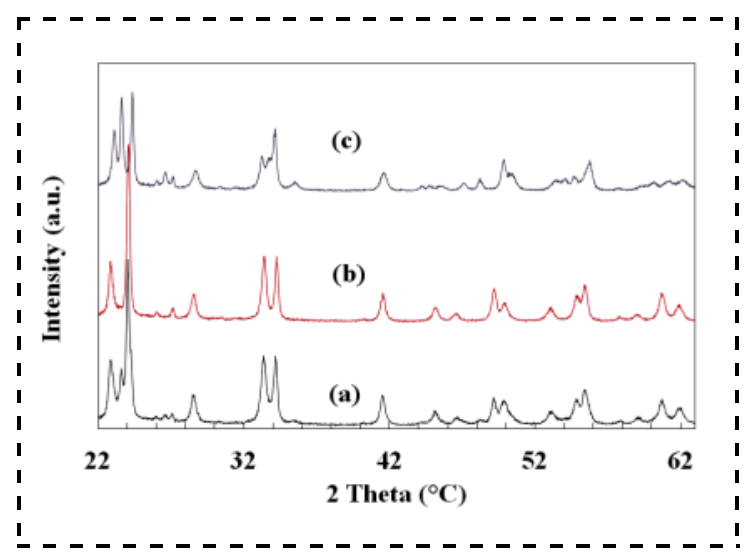

Fig. 4. XRD patterns of (a) monoclinic phase of pure $\mathrm{WO}_{3}$ after 16 hours in contact with 3\% diluted hydrogen in $\mathrm{N}_{2}$; (b) formation of tetragonal hydrogen tungsten bronze in $\mathrm{Pd}-\mathrm{WO}_{3}$ after 60 minutes in contact with $3 \%$ diluted hydrogen in $\mathrm{N}_{2}$ and (c) monoclinic phase of $\mathrm{WO}_{3}$ in Pd-loaded $\mathrm{WO}_{3}$ after 16 hours in contact with $3 \%$ hydrogen diluted in $\mathrm{O}_{2}$.

Tab. 1: Summary of the change in the crystal phases obtained by XRD analysis of pure $\mathrm{WO}_{3}$ and $\mathrm{Pd}$-loaded $\mathrm{WO}_{3}$ in contact with hydrogen (3\% diluted hydrogen in synthetic air/or diluted in nitrogen).

\begin{tabular}{|c|c|c|c|}
\hline $\mathrm{T} /{ }^{\circ} \mathrm{C}$ & Sample & Atmospheres & $\begin{array}{c}\text { Crystal } \\
\text { phase }\end{array}$ \\
\hline 200 & $\begin{array}{c}\text { Pure } \\
\mathrm{WO}_{3}\end{array}$ & $\begin{array}{c}3 \% \text { of } \mathrm{H}_{2} \\
\text { diluted in air }\end{array}$ & $\begin{array}{c}\text { Monoclinic } \\
\mathrm{WO}_{3}\end{array}$ \\
\hline $27-$ & $\begin{array}{c}\mathrm{Pure} \\
\mathrm{WO}_{3}\end{array}$ & $\begin{array}{c}3 \% \text { of } \mathrm{H}_{2} \\
\text { diluted in } \mathrm{N}_{2}\end{array}$ & $\begin{array}{c}\text { Monoclinic } \\
\mathrm{WO}_{3}\end{array}$ \\
\hline 200 & $\begin{array}{c}\mathrm{Pd} \\
\mathrm{WO}_{3}\end{array}$ & $\begin{array}{c}3 \% \text { of } \mathrm{H}_{2} \\
\text { diluted in air }\end{array}$ & $\begin{array}{c}\text { Monoclinic } \\
\mathrm{WO}_{3}\end{array}$ \\
\hline 200 & $\begin{array}{c}\mathrm{Pd} \\
\mathrm{WO}_{3}\end{array}$ & $\begin{array}{c}3 \% \text { of } \mathrm{H}_{2} \\
\text { diluted in } \mathrm{N}_{2}\end{array}$ & $\begin{array}{c}\text { Tetragonal } \\
\mathrm{H}_{\mathrm{x}} \mathrm{WO}_{3}\end{array}$ \\
\hline 200
\end{tabular}

\section{Conclusions}

$\mathrm{Pd}$-loaded $\mathrm{WO}_{3}$ nanocomposites were prepared and characterized. Thick films based on the prepared nanocomposites were fabricated and their sensing properties to hydrogen in the ppm level were measured under various conditions (temperatures and humidities). The sensors showed high performances (response, response time and recovery times) to hydrogen in the ppm level (50-200 ppm).
Hydrogen sensing mechanism of $\mathrm{Pd}-\mathrm{WO}_{3}$ was studied. In-situ characterizations of the changes in the crystal phases and the surface coloration (formation of hydrogen tungsten bronze) for different operating conditions were performed indicting the formation of a bronze with hydrogen in the surface but not in the bulk in presence of oxygen. These observations are attributed to the competition between reduction of $\mathrm{W}^{+6}$ to $\mathrm{W}^{+5}$ (formation of hydrogen tungsten bronze) and its oxidation $\left(\mathrm{W}^{+5}\right.$ to $\left.\mathrm{W}^{+6}\right)$. In the presence of oxygen, the oxidation is predominated. The sensing mechanism can be modeled. More experimental results and explanations will be presented and discussed.

\section{Acknowledgements}

This work was carried out in the fromwork of the Cold-Plasma project of the University of Mons, financially supported by the Communauté Française de Belgique. and also in the framework of the Opti ${ }^{2}$ mat "Programme Excellence" supported by the Walloon Region of Belgium.

Rony Snyders acknowledge the Belgian Government through the "Pôle d'Attraction Interuniversitaire " (PAI, P6/08, "PlasmaSurface Interaction", $\Psi$ ).

\section{References}

[1] M. Hübner, C.E. Simion, A. Haensch, N. Barsan, $\mathrm{U}$. Weimar, $\mathrm{CO}$ sensing mechanism with $\mathrm{WO}_{3}$ based gas sensors Sensors and Actuators $B$ : Chemical 151, 103-106 (2010); doi: 10.1016/j.snb.2010.09.040

[2] J.K. Srivastava, Preeti Pandey, V.N. Mishra, R. Dwivedi, Sensing mechanism of Pd-doped $\mathrm{SnO}_{2}$ sensor for LPG detection, Solid State Sciences 11, 1602-1605 (2009); doi: 10.1016/j.solidstatesciences.2009.06.014

[3] A. Boudiba, C. Zhang, C. Navio, C. Bittencourt, R. Snyders, M. Debliquy, Procedia Engineering 5,180-183 doi:10.1016/j.proeng.2010.09.077

(2010);

[4] C. Zhang, M. Debliquy, A. Boudiba, H. Liao and C. Coddet, Sensing properties of atmospheric plasma-sprayed $\mathrm{WO}_{3}$ coating for sub-ppm $\mathrm{NO}_{2}$ detection, Sensors and Actuators B 144, 280288 (2010); doi.org/10.1016/j.snb.2009.11.006 